\title{
Efeito da prática de trabalhos manuais sobre a autoimagem de idosos
}

Effects of practice on manual works for the self-image of the elderly

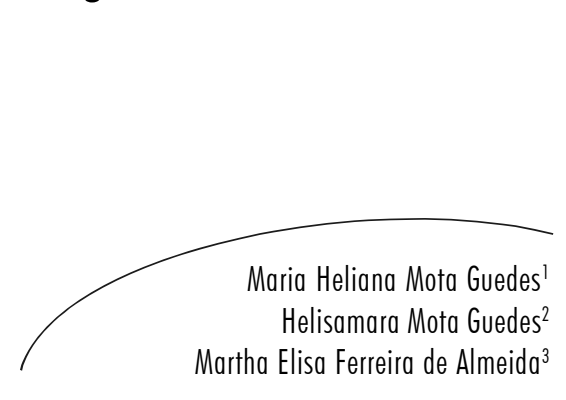

A população mundial vem envelhecendo com rapidez; assim, a expectativa de vida vem aumentando e as pessoas estão prolongando seus anos de vida. A arte permite ao ser humano a liberação de seus sentimentos e emoções, aumentando a qualidade afetiva das relações interpessoais, pela melhora da comunicação, fortalecimento da autoimagem e redescoberta de potenciais criativos. Este trabalho teve como objetivo investigar de que forma a prática dos trabalhos manuais pode influenciar a autoimagem do idoso. Avaliou-se a arte através de entrevistas semiestruturadas, centradas em questões relacionadas com o envelhecimento e a autoimagem como recurso terapêutico, de criatividade, processo da criação, autoimagem, autoconceito, autoestima, sentimento e emoções. Evidenciou-se que os trabalhos manuais fortaleceram a autoimagem do idoso, através da concretização dos trabalhos, assim como a socialização, minimizando eventuais impactos decorrentes do envelhecimento, e até mesmo permitindo surgir habilidades artísticas e seu aprimoramento. Conclui-se através da categoria benefícios e das subcategorias habilidade mental, socialização e remédio, que as atividades manuais são valiosas ferramentas na recuperação biológica, psicológica, social e imunológica dos idosos.

\section{Abstract}

The world population is aging rapidly; thus life expectancy is increasing and people are extending their years of life. Art enables man to release their feelings and emotions, increasing the affective quality of interpersonal relationships by improving communication, strengthening self-image and rediscovery of creative potentials. This study aimed to investigate how the practice of manual works

1 Curso de Pós-Graduação em Gerontologia. Universidade Católica de Brasília. Brasília, DF, Brasil.

2 Departamento de Enfermagem. Universidade Federal dos Vales do Jequitinhonha e Mucuri. Diamantina, MG, Brasil

3 Curso de Nutrição. Universidade Federal de Viçosa, Campus de Rio Paranaíba. Paranaíba, MG, Brasil.
Palavras-chave: Idoso. Arte. Terapia pela arte. Atividades de lazer. Trabalhos manuais. 
can influence the self-image of the elderly. It evaluated art through semi-structured interviews, focusing on issues related to aging and self-image as a therapeutic, creative, artistic process, self-image, self-concept, self-esteem, feelings and emotions. It was evident that the crafts strengthen self-image of the elderly, through the completion of the work, as well as socialization, minimizing any impacts associated with aging, and even arising artistic skills and their improvement. It is through the benefits category and subcategories: mental ability, socialization, and medicine, that manual activities are valuable tools in recovering biological, psychological, social and immunological elderly.
Key words: Elderly. Art. Art therapy. Leisure activities. Manual works.

\section{INTRODUÇ̃̃OO}

A perspectiva de aumento de vida vem se tornando uma realidade mundial. A previsão é que em 2020 haja mais de um bilhão de pessoas com mais de 60 anos em todo o mundo. ${ }^{1}$ Conforme dados do Instituto Brasileiro de Geografia e Estatística (IBGE), o Brasil possui uma proporção de 78,6 homens idosos para cada 100 mulheres idosas (idade $\geq 60$ anos). ${ }^{2}$

Para a grande maioria, a velhice é uma etapa da vida cercada por impedimentos e constrangimentos, das mais diversas ordens. Estar envelhecendo implica enfrentar transformações no corpo e na vida social. As mudanças na vida social, como a chegada da aposentadoria, são bem mais difíceis de serem compreendidas do que os limites que o corpo começa a impor à medida que a idade avança. Em muitos casos, junto ao tempo livre que decorre de situações como a aposentadoria, aparecem também sentimentos negativos que podem se transformar em problemas como a depressão e a solidão. Quando isso acontece, a arte, além de socializar, permite ao homem liberar sentimentos e emoções. Ela mantém as experimentações criativas e expressivas e funciona como fator ativador de núcleos de vitalidade e de comunicação.

Segundo Fortuna, ${ }^{3}$ a arte sempre expressou situações vividas pelo ser humano, desde a préhistória até os dias atuais, independentemente do grau de desenvolvimento cultural das sociedades. Cada atividade, cada material, cada cor, forma, movimento e som, tem uma possibilidade de atuação no sujeito. ${ }^{4}$ Assim, um rolo de barbante pode permitir a percepção e integração de noções de especialidade. As cores, quando bem utilizadas, podem permitir a expressão afetiva e emocional. A modelagem permite estimulação tátil, o trabalho muscular, a estrutura postural, assim como a capacidade de expressão e de planejar. A técnica do desenho tem, na terapia pela arte, o papel de desenvolver a esfera cognitiva, além da capacidade de abstração. Os fios (lãs, barbantes e linhas) utilizados no bordado, tricô, crochê e tecelagem permitem o fortalecimento e a reeducação do pensamento. A imagem sonora faz entrar em contato com seu "eu" mais profundo, que, seguindo as melodias e ritmos, equilibram e harmonizam o sujeito. A dança, além de sua excelência na projeção das imagens internas, permite a exploração e o uso do corpo no espaço.

A utilização da arte no processo terapêutico permite identificar nas imagens, música e escrita, representações de suas expressões, seus sentimentos, pensamentos e sensações naquele momento da vida. ${ }^{3}$ Segundo Fabiette, ${ }^{5}$ a arte como recurso terapêutico é uma atividade na qual se usam técnicas expressivas, ou seja, a expressão artística. Neste sentido, a arte não requer uma preocupação estética, o objetivo é somente possibilitar e facilitar a comunicação. Não é necessário "fazer bonito", porque o que importa na arteterapia é o significado do que se faz. A terapia pela arte não necessariamente se fixa nos limites clássicos da psicoterapia através da linguagem artística, uma vez que na Fonoaudiologia, Fisioterapia, Enfermagem, Psicopedagogia e Terapia Ocupacional a arte também é utilizada como a Terapia pela Arte. ${ }^{4}$

Muitos idosos sentem-se desolados e fragilizados ao se defrontarem com seu próprio 
envelhecimento, com os preconceitos da idade, a aposentadoria e o declínio gradual das aptidões físicas. As doenças muitas vezes podem ocasionar uma redução no desempenho físico, na habilidade motora, na capacidade de concentração, reação e coordenação, gerando o processo de desvalorização $\mathrm{da}$ autoimagem, apatia, insegurança, perda da motivação, isolamento social, solidão e baixa autoestima. Este quadro tende a ser alterado se forem desenvolvidas, com os idosos, atividades de expressões artísticas, que visam à melhoria das capacidades motoras que apoiam a realização de sua vida cotidiana, enfatizando o bem-estar e a autoimagem.

Na busca pela confirmação desses benefícios promovidos pela arte, este trabalho teve como objetivo investigar de que forma a prática dos trabalhos manuais pode influenciar a autoimagem do idoso.

\section{METODOLOGIA}

Trata-se de uma pesquisa de caráter exploratório e qualitativo. Os dados foram obtidos após aprovação do Comitê de Ética em Pesquisa da Universidade Católica de Brasília (UCB), protocolo n. 54/2006. Para a realização da pesquisa, foi concedida autorização do responsável pela instituição, assim como a liberação para citar o nome do Programa Humanizar.

O município de Timóteo, no Vale do Aço, Minas Gerais, desenvolve o Programa Humanizar. Ele foi iniciado em fevereiro de 1992 com 15 alunos da terceira idade, sendo que em 2007 funcionava em dez núcleos, em vários bairros $\mathrm{da}$ cidade e havia aproximadamente 1.500 alunos de ambos os sexos. O programa é mantido pela Prefeitura Municipal de Timóteo em todas as suas despesas.

Segundo a Secretaria Municipal de Educação de Timóteo, o Programa Humanizar recebe alunos a partir de 40 anos, como forma de prevenção de doenças crônicas não-transmissíveis. Pessoas de diferentes classes sociais e de diferentes níveis de escolaridade integram o programa, criando laços afetivos e de amizade. Ainda de acordo com a secretaria, os professores do programa desenvolvem as mais variadas atividades, como dança, ginástica localizada e recreativa, alongamento, hidroginástica, massagem, caminhada, teatro, dramatização, contação de histórias, coral e trabalhos manuais (pintura, bordado, crochê, macramê e artesanato variado). O programa também oferece palestras, seminários, encontros e viagens, buscando informar os integrantes sobre os cuidados com a saúde, benefícios da arte, importância das atividades físicas, direitos do idoso e outros assuntos escolhidos pelos participantes, com o intuito de promover a prevenção, promoção e reabilitação da saúde. A proposta do programa era ter como público alvo pessoas da terceira idade, mas recebia adultos a partir de 40 anos como forma de prevenção do envelhecimento. Ao analisar o perfil de quem frequentava o Programa Humanizar, observou-se que ele era bastante diversificado e podia ser dividido em três subgrupos.

No primeiro subgrupo, encontravam-se as pessoas de 40 a 60 anos (40\% do total dos participantes do programa) que apenas queriam fazer atividade física, cuidarem da saúde sob a supervisão de profissionais de saúde, incluindo um médico do Programa de Saúde da Família que atendia nos bairros onde o Programa Humanizar estava inserido, e ter um ambiente de encontro com pessoas da mesma comunidade e faixa etária. No segundo, encontravam-se aqueles que receberam orientação médica para fazerem exercícios sob a supervisão de fisioterapeutas e educadores físicos, e quando necessário faziam acompanhamento com psicólogos. Eram pessoas com a idade de 61 a 80 anos (50\% do total dos participantes do programa) que passaram por cirurgias ou sofriam de doenças como hipertensão arterial, diabetes mellitus e outras doenças crônicas não-transmissíveis. Segundo relatos dos membros deste subgrupo, seus familiares não mediam esforços para o acompanhamento no programa, pois havia o entendimento de que a ação conjunta interferia positivamente na melhora da condição de saúde dessas pessoas. E no terceiro subgrupo 
estavam as pessoas com mais de 80 anos $(10 \%$ do total dos participantes do programa) que só faziam atividades acompanhadas e específicas por requererem mais atenção.

O Programa Humanizar atende como trabalho de cunho social principalmente, mas não deixava de possuir caráter terapêutico, porque tinha profissionais especialistas e de arte terapêutica, nas áreas da arte, artesanato, música, teatro e dança. Por todas essas ações desenvolvidas, definiu-se que o programa possuía caráter terapêutico, arte terapêutico, cultural e artístico.

Enviou-se um convite aos idosos (idade $\geq 60$ anos) de ambos os sexos que participavam do programa e que frequentavam há mais de um ano as aulas de trabalhos manuais, em um dos dez núcleos do Programa Humanizar, para participar do estudo. Selecionaram-se participantes de quatro núcleos, uma vez que não eram todos os núcleos que desenvolviam os trabalhos manuais. Os critérios de exclusão foram: a recusa em participar da pesquisa através da não assinatura no termo de consentimento livre e esclarecido, o ingresso nas aulas de trabalhos manuais há menos de um ano e idade inferior a 60 anos. A amostra final foi composta de 22 idosas.

Aplicou-se a modalidade de entrevista semiestruturada oral, pela riqueza de dados nas respostas, com duração prevista de aproximadamente 90 minutos, gravada e posteriormente transcrita. A entrevista foi centrada em questões relacionadas a arte, trabalhos confeccionados, criatividade, autoimagem, sentimentos e emoções, considerando-se, para tanto, a interligação terminológica entre o construto autoimagem e os vocábulos autoestima e autoconceito. Para efeito desta pesquisa, as expressões autoconceito, autoimagem e autoestima tiveram, respectivamente, o significado de consciência do eu, representação do eu e percepção afetiva de si. $^{6}$

A observação dos participantes aconteceu durante as aulas de trabalhos manuais, cujos itens preestabelecidos para descrição foram: socialização, autoimagem, dedicação às aulas, aceitação dos trabalhos pela família e a sociedade, emoções explicitadas durante a confecção dos trabalhos e criatividade. Realizou-se essa atividade no período de três meses, com um encontro semanal, totalizando 30 sessões de observação, já que as aulas de trabalhos manuais eram realizadas uma vez por semana, durante três horas consecutivas. Através dos trabalhos manuais desenvolvidos, foi possível observar a evolução da criatividade dos participantes.

Os participantes foram informados sobre os objetivos e finalidades do trabalho, e assinaram o termo de consentimento livre e esclarecido com base na Resolução n. 196/96. ${ }^{7}$

\section{RESULTADOS}

A caracterização da amostra encontra-se na tabela 1. A faixa etária que predominou neste estudo foi de 60 a 65 anos. $O$ estado conjugal mais frequente foi o de idosas casadas, com 59,0\%. As idosas viúvas, solteiras, divorciadas ou separadas residiam com os filhos, parentes ou viviam sós. 
Tabela 1 - Frequência absoluta e porcentagem das idosas segundo o perfil sociodemográfico. Timóteo, MG, 2006.

\begin{tabular}{|c|c|c|}
\hline Variável & $N$ & $\%$ \\
\hline \multicolumn{3}{|l|}{ Idade (anos) } \\
\hline $60-65$ & 14 & 63,6 \\
\hline $66-70$ & 4 & 18,1 \\
\hline $71-75$ & 2 & 9,9 \\
\hline $76-80$ & 1 & 4,5 \\
\hline$\geq 81$ & 1 & 4,5 \\
\hline \multicolumn{3}{|l|}{ Estado Conjugal } \\
\hline Casada & 13 & 59,0 \\
\hline Viúva & 7 & 31,8 \\
\hline Solteira & 2 & 9,9 \\
\hline Divorciada/Separada & - & - \\
\hline \multicolumn{3}{|c|}{ Com quem reside atualmente } \\
\hline Cônjuge & 13 & 59,0 \\
\hline Filhos & 3 & 13,6 \\
\hline Irmãos/Parentes & 1 & 4,5 \\
\hline Sozinha & 5 & 22,7 \\
\hline \multicolumn{3}{|l|}{ Números de filhos (vivos) } \\
\hline $0-2$ & 3 & 13,6 \\
\hline $3-4$ & 7 & 31,8 \\
\hline $5-6$ & 5 & 22,8 \\
\hline $7-9$ & 3 & 13,6 \\
\hline$>10$ & 1 & 4,5 \\
\hline Nenhum & 3 & 13,6 \\
\hline \multicolumn{3}{|c|}{ Realizavam tratamento de saúde } \\
\hline Sim & 10 & 45,0 \\
\hline Não & 12 & 55,0 \\
\hline \multicolumn{3}{|l|}{ Doença tratada } \\
\hline Cardiovasculares & 2 & 9,9 \\
\hline Osteoporose & 3 & 13,6 \\
\hline Depressão & 4 & 19,8 \\
\hline Diabetes mellitus & 3 & 13,6 \\
\hline Hipertensão arterial & 6 & 37,3 \\
\hline
\end{tabular}

Das 12 entrevistadas que não realizavam nenhum tratamento médico, três tiveram alta do tratamento de depressão após iniciar a prática dos trabalhos manuais.
Quanto ao número de doenças por participantes, nota-se que houve prevalência de duas doenças em $31,8 \%$ da amostra, seguidos por 9,9\% com três doenças (tabela 2 ).

Tabela 2 - Frequência absoluta e porcentagem do número de doenças por participante. Timóteo, MG, 2006.

\begin{tabular}{cccc}
\hline Números de doenças & $N$ & $\%$ \\
\hline 1 & 1 & $4.5 \%$ \\
2 & 7 & $31.8 \%$ \\
3 & 2 & $9.9 \%$ \\
Nenhuma & 12 & $54.5 \%$ \\
\hline
\end{tabular}


Após a leitura do corpus coletado, procedeu-se à categorização das respostas obtidas. As unidades textuais da entrevista foram sublinhadas, enumeradas, recortadas, coladas e agrupadas, de acordo com algumas semelhanças entre as respostas obtidas. As participantes foram denominadas por E maiúsculo, seguida pela numeração arábica de 1 a 22.

Foram ressaltadas situações específicas dos discursos proferidos pelas participantes, procurando relacionar fragmentos frasais com as respostas. Nesse sentido, a categorização dos sentimentos foi criada com base nas informações prestadas pelas depoentes.

Visando à organização temática, foram avaliadas a categoria "benefício" e as subcategorias "habilidade mental", "socialização" e "remédio". A categoria "benefício" consiste em mostrar, dentro do universo pesquisado, as falas que apresentavam efeitos positivos decorrentes $\mathrm{da}$ atividade de trabalhos manuais.

$\mathrm{Na}$ subcategoria habilidade mental, os benefícios observados situam-se no plano da retenção de informação.

1. [...] Agora parece até que a mente voltou com os bordados, acho que a gente força a mente e ela volta (E13). Recuperação da habilidade de retenção de informação.

2. [...] Eu notei que minha mente evoluiu muito mais e o espirito também (E3). Marca da evolução mental.

3. [...] Minha cabeça melhorou, porque tem que concentrar, contar os pontinhos, tem que trabalhar a cabeça mesmo, senão faço tudo errado, melhorei muito a cabeça (E6). Resgate de habilidades de memorização.

4. [...] Minha mente melhorou muito, estou ainda esquecida, mas mesmo assim melhorou demais... até risco as amostras de cabeça (E7). Revelação de retomada de habilidade mental.

5. [...] Depois que começon a ter essas aulas, esses trabalhos, parece que minha mente está voltando, ficando mais ativa (E4). Revelaşão da retomada da atitude mental.
6. [...] Esses trabalhos também ajudam na memória en acredito, principalmente assim, pra quem tem mais dificuldade, ajuda muito (E8). Confirmação do trabalho manual como possibilidade de reaver a memória.

7. [...] Estou movimentando a mente, estava muito esquecida, só esquecendo as coisas... aqui na aula trabalha sua mente ... Tem que contar muito para não errar (E12). Reforça a intensidade da operação mental na tentativa de não cometer erros.

8. [...] Antes de en fazer estes trabalhos en tinha uma sensação de estar doente, adoeci mesmo, mas vim pra cá fui ficando e a minha memória melhorou demais, eu não guardava nada na minha cabeça. Minha memória melhorou acho que é porque eu não tenho mais aquela sensação de estar doente, meu sentimento agora é de saúde (E15). Revelação de uma mudança em sua qualidade de vida, que passa a ter mais saúde ao recuperar a memória.

9. [...] Minha memória melhorou muito, porque tem que concentrar muito. Eu bordo todos os dias (E18). Como característica do bordado, a necessidade de retenção de informações prévias para produz̨ir novos trabalhos, dai a importância da atividade rotineira na retenção da memória.

$\mathrm{Na}$ subcategoria socialização, resgata-se a importância dos trabalhos manuais na busca do seu encontro com o outro que pode ser uma colega ou alguém que possa ser a extensão da sua família.

1. [...] Além dos trabalhos tem o contato com as colegas, conversa com um, com outro, você está junto com todo mundo, vai embora conversando com uma turma, vem desabafando com outra, porque eu passei a viver de novo depois que fiquei viúva, agora minha vida está muito boa (E4). Resgata a necessidade que uma pessoa solitária tem de buscar no outro a completude do seu eu social.

2. [...] Aqui a gente pode conversar bastante, posso sorrir, conviver, e é bom demais conviver com as colegas, com as pessoas (E5). Reforça a importância do trabalho manual do coletivo na dinâmica da convivência bumana.

3. [...] Aqui é muito bom tem as amizades né? Conversa com um, com outro, eles dão opinião no 
meu trabalho (E6). Marca a importância da amizade, na troca mútua, nas relações humanas.

4. [...] Aqui eu tenho as amigas, fico no meio delas e fico muito bem, elas me ajudam a lembrar e a renovar os bordados que aprendi quando era criança (E15). Resgata a necessidade do ser bumano de se encontrar em grupo.

5. [...] Eu fico no meio das pessoas diferentes, a gente sente bem de ficar com outras pessoas (E3). Revela a necessidade do ser humano viver socialmente.

6. [...] Mas aí vêm as colegas, a gente encontra, bate papo, é muito bom (E8). Aborda o poder do diálogo como forma de se encontrar e encontrar o outro.

7. [...] Participo também para conviver, e passar para as pessoas que querem aprender, quem quer eu ensino (E9). Apresenta a satisfação pessoal na transmissão de informações que serão importantes na vida do outro.

8. [...] Aqui nas aulas você está no seu meio, aqui você é valorizada, as pessoas gostam de você, você ajuda as colegas, elas te ajudam, é uma satisfação se sentir útil (E13). Reafirma a importancia das relações mútuas na realização de um trabalho manual coletivo.

9. [...] Passei a me sentir bem melhor, a gente faz. amigos. Me dá alegria quando chego aqui, a sala parece uma sala de irmãos, é muito gostoso (E14). Apresenta o ambiente coletivo favorável ao relacionamento que cria lacos afetivos.

10. [...] Eu acho tão bom estar aqui no meio do pessoal, porque, além dos bordados, eu ainda tenho as pessoas, que a gente diverte muito, brincando, batendo papo, a gente é muito amiga (E16). Marca a possibilidade de criação de um grupo fundamentado em laços afetivos e com ênfase em parceria.

11. [...] Essas aulas são muito boas para conversarmos com as colegas, é o entrosamento, e tem hora que sai alguma piadinha que a gente ri bastante, relaxa, né? É a convivência e isto é muito importante, principalmente pra mim que vivo só (E17). Revela a importância da descontração e do humor na realização do trabalho manual coletivo.

12. [... I Isto aqui é uma oportunidade, sair de casa, ter contato com um, com outro, poder aprender aqui $e$ até depois ensinar o que a gente aprendeu aqui (E19). Apresenta a realização bumana na troca de conhecimento, além da saída de cas a como evento social.

$\mathrm{Na}$ subcategoria remédio, há uma possibilidade de situar conceitualmente os efeitos decorrentes dos trabalhos manuais naqueles que os praticam. Há nessa subcategoria um meio de terapia contra problemas fisiológicos, imunológicos, sociais e psicológicos.

1. [...] Eu guardo meus bordados, fico felizem ficar pegando neles, dou de presente, forro meus negocinhos (E 3). Revela a aplicação terapêutica que os bordados representam.

2. [...] Eu tenho uma sobrinha que levou e vendeu tudo, já mandou o dinbeiro pra mim, é bom demais, guardei ele todo na poupança para viajar com o Programa Humanizar, é dinheiro do meu serviço, agora não precisa de mais ninguém me dar dinheiro (E 4). Registra a importância socioeconômica gerada pela produção de trabalhos manuais na busca da sobrevivência.

3. [...] Meus trabalhos, eu dou na maior alegria, não vendo os panos; o importante não éo dinheiro é a satisfação da pessoa que ganha o presente e minha alegria em saber que ela gostou e ficou toda satisfeita (E 5). Possibilita a leitura que a capacidade de doação pode significar para aquele que produz um trabalho manual e, ao fazer dele um presente, se realiza com a satisfação de quem recebeu.

4. [...] Conheci várias pessoas na mesma situação minha, na mesma idade, então pra mim foi um remédio, mudou até minha auto-estima, eu me senti mais capaz, até em outros sentidos, não só no artesanato, mas eu senti vontade de fazer outras coisas, então melhorou todo meu ser (E 13). Demonstra um efeito global no organismo humano, uma vez que esta terapia tem a possibilidade de promover um encontro consigo mesmo e em direção ao outro.

5. [...] Esse trabalho me ajudou muito, até ajudou a controlar minha pressão porque é um relaxamento, me traz uma sensação de paz e equilíbrio (E 10). Reforça, mais uma vez, a capacidade terapêutica que as atividades manuais coletivas desencadeiam no indivíduo. 
6. [...] Depois que entrei nos bordados minha vida mudou, estou mais tranquila, alegre, gosto de fazer as coisas, não gosto de ficarparada (E 11). Declara que a prática da atividade manual é capaz de proporcionar alegria, tranquilidade às pessoas, procurando sair da inércia.

7. [...] Depois que eu comecei a fazer esses bordados eu fiquei menos nervosa, volto a falar, esses trabalhos são como remédios pra mim, se alguém for me impedir de bordar um dia eu prefiro morrer, não consigo nem pensar o que seria de minha vida sem bordar ( $E$ 18). Revela a necessidade "deste medicamento" na continuidade de uma vida mais equilibrada e feli;:

8. [...] Depois que comecei a fazer estes trabalhos, não somente eu, mas lá em casa meu marido e minha filha perceberam mudanças, eu fico menos cansada, estou aceitando as coisas com mais maturidade, menos nervosismo (E 19). Estabelece uma ação sedativa na vida de uma mãe, mulher, dona de casa que percebe nos trabalhos manuais uma possibilidade de controlar a simesma.

9. [...] Eu guardo tudo para mim, todo mundo que chega eu mostro com muito orgulho (E 5). Define a realização do ser bumano por meio de trabalhos manuais em um ser útil e capaz:

10. [...] Inclusive eu e algumas colegas já estamos ensinando os trabalhos daqui, no salão São Vicente (E 7). Estabelece a ação de multiplicar o conhecimento; uma satisfação pessoal que a torna ainda mais feliz:

11. [...] Depois que eu passei a me dedicar a esses trabalhos en fiquei mais tranquila; eu era muito ansiosa, agora vejo que esses trabalhos me ajudam muito, além de ser muito bom pra minha mente ( $E$ 17). Retoma, mais uma vez, o efeito psicossomático que promove a desconcentração, a ação antidepressiva naqueles que participam de atividades manuais.

\section{DISCUSSÃO}

A viuvez ou a separação podem trazer a possibilidade de liberdade e alegria, isto quando houve uma relação de autoritarismo e posse em relações anteriores. ${ }^{8}$ Santos ${ }^{9}$ recomenda o convívio familiar e o contato com as amigas, pois o carinho e o afeto são imprescindíveis contra o envelhecimento social, sendo o idoso um ser integrante da família e da sociedade.

Conforme dados do Instituto Brasileiro de Geografia e Estatística (IBGE), existem cinco mulheres viúvas para cada homem viúvo, ${ }^{2}$ sendo sugerido que tal fato ocorre porque as mulheres se casam mais jovens que seus maridos, além de possuírem maior longevidade e dificilmente se casarem novamente. ${ }^{10}$ As mulheres idosas apresentam maior tendência a viver sozinhas, devido ao fato de que grande parte delas são viúvas e uma proporção cada vez maior são separadas ou divorciadas. ${ }^{11}$

Neste estudo, houve uma prevalência de duas doenças em $31,8 \%$ da amostra, seguidos por $9,9 \%$ com três doenças, sendo as mais citadas a hipertensão arterial (37,3\%) e a depressão (19,8\%). Quintão et al., ${ }^{12}$ ao avaliarem idosos com incontinência fecal, observaram que $73,9 \%$ tinham menos de três patologias associadas, sendo as mais frequentes: acidente vascular encefálico, diabetes mellitus e hipertensão arterial.

Segundo Camarano, ${ }^{11}$ existem doenças que antes de representar um risco de vida, ameaçam a independência e a autonomia do indivíduo. Souza ${ }^{13}$ ressalta que o fazer com as mãos pode não curar as doenças, nem eliminar limitações inerentes à idade avançada, mas pode auxiliar na amenização da dor ou no encontro de uma mudança mais positiva em relação à vida e ao modo de ser, ou despertar a vontade de buscar a vontade da própria felicidade. Carvalho ${ }^{14}$ destaca que, através das atividades artísticas, o paciente poderá expressar seus sentimentos, pensamentos, emoções e atitudes.

Stuart-Hamilton ${ }^{15}$ relata que muitas habilidades intelectuais, particularmente as que dependem da inteligência fluida declinam com a velhice, tornando-se mais lentas e menos exatas. Entretanto neste estudo, nove (40,9\%) participantes avaliadas relataram que os trabalhos manuais melhoraram suas habilidades mentais.

Das participantes avaliadas, 12 (54,5\%) relataram que os trabalhos manuais foram 
importantes para sua socialização. A criação de um trabalho garante a autoestima e a autoconfiança. Reforçando o ego, a arteterapia direciona a subjetividade, tornando-se cada vez mais estruturada no percurso de sua autonomia ou autoria de pensamento. Favorecendo a relação com o outro, o indivíduo tem a possibilidade de se sentir incluído ou fazer parte de um grupo, desenvolvendo sentimentos de companheirismo, satisfação, identificação, semelhança, apoio, proteção e ajuda..$^{16}$

Carvalho ${ }^{14}$ destaca que a arte faz parte do convívio humano como necessidade, além de contribuir para o desenvolvimento global. $\mathrm{O}$ indivíduo desenvolve formas de se expressar e registrar sua marca pessoal, o estilo e seu modo de estar no mundo, assim como comunicar e expressar sentimentos. A arte tem forte papel social, além de facilitar um despertar para as emoções. Em qualquer manifestação artística como a música, pintura e o teatro, o artista expressa simbolicamente suas sensações, sentimentos e imagens do seu mundo interior, e proporciona ao público participante o contato com essas emoções. Relatos das participantes E14 e E16 na subcategoria da socialização reforçam tal ideia.

Os relatos das participantes E17 e E19 na subcategoria da socialização reforçam que a arteterapia trabalhada em grupo possibilita tanto $\mathrm{o}$ alcance de objetivos pessoais e sociais, uma vez que ela favorece a personalidade em formação, o caminho de integrar-se às necessidades de adaptação às exigências externas do grupo. ${ }^{16}$

Das participantes avaliadas, 11 (50,0\%) relataram que os trabalhos manuais tinham efeitos terapêuticos. Fortun $a^{17}$ destaca que a produção artística não deve ser avaliada na sua qualidade estética, mas na avaliação contínua de um processo de fazer arte na infinitude de alternativas possíveis, verificando até que ponto ele pode recuperar seu estado saudável. Deve incentivar a pessoa a lidar melhor com seus conteúdos internos, com o objetivo de ajudá-lo a reequilibrar-se emocionalmente e encontrar sua própria linguagem expressiva, por meio da qual possa entender seus conflitos, expressar suas emoções, seus traumas e desejos.
A arte tem uma função simbólica, pois permite ao indivíduo expressar-se e perceber significados. Em todas as épocas, a arte teve sua função e serviu para diferentes propósitos, mas sempre revelou e destacou o homem no mundo. ${ }^{18}$

Segundo Carvalho, ${ }^{14}$ a busca das artes como elemento facilitador de expressividade da alma, de pensamento e percepção é uma excelente condição de aprendizagem para reconstruir atitudes e escutar as dores e anseios da alma. Assim, a obra artística é um verdadeiro registro da alma de seu autor, que se manifesta em uma linguagem muito peculiar, com símbolos particulares ao contexto do momento histórico e particular ao contexto terapêutico, podendo esta obra ser considerada um espelho do mundo interno de seu autor, revelando não apenas suas características pessoais (possibilidades e limites), suas potencialidades, mas inclusive a maneira como este se organiza em seus relacionamentos intrapessoais, interpessoais e com o mundo.

Para Ostrower, ${ }^{19} \mathrm{o}$ homem cria não apenas por vontade própria ou porque gosta e sim porque precisa. E ele só pode crescer de maneira coerente como ser humano, ordenando, formando e criando. Carvalho ${ }^{14}$ ressalta que o crescimento pessoal e holístico é favorecido pela arte. "O uso da arte como terapia implica um processo criativo que pode ser um meio tanto de reconciliar conflitos emocionais, como de facilitar a autopercepção e o desenvolvimento pessoal". Souz ${ }^{13}$ relata que envelhecer com satisfação depende do delicado equilíbrio entre as limitações $\mathrm{e}$ as potencialidades do indivíduo. Trabalhando com o idoso, faz-se necessário o encontro da criação com as independências físicas e psicológicas. As ciências vêm apontando a arte como meio de conseguir bem-estar e atividade, permitindo assim, dizer que um dos pilares de uma velhice saudável é a harmonia na expressão dos sentimentos, naquilo que o idoso faz para manter em atividade a mente e o corpo.

A autoestima é a avaliação da pessoa sobre seu próprio valor, dependendo da percepção de si mesma e abrange dois componentes: o sentimento de competência pessoal e o sentimento de valor 
pessoal. $^{20}$ É a soma da autoconfiança com o autorrespeito e reflete a capacidade pessoal de se lidar com as dificuldades da vida e com o direito de ser feliz. ${ }^{21}$ Segundo Erbolato e Leite ${ }^{22}$ a autoestima implica uma visão geral de como somos e de como achamos que os outros nos veem. Entram neste processo aspectos emocionais e intelectuais, em que a autoestima, por si só, já supõe uma avaliação positiva. ParaSimmons et al., ${ }^{23}$ pela autoestima avaliase se alguém quer bem a si próprio.

Sanchez e Escribano ${ }^{24}$ definem autoconceito como uma atitude valorativa do indivíduo acerca de si mesmo envolvendo estima, sentimentos, experiências ou atitudes que o indivíduo desenvolve sobre si mesmo. O autoconceito tem papel fundamental sobre o psiquismo do indivíduo, sendo muito importante para suas experiências, saúde psíquica, e atitudes para consigo e para os demais, base para a construção da personalidade. $\mathrm{Na}$ velhice, o bem-estar psicológico caracteriza-se pela autoaceitação, pela autonomia, pelas relações mais positivas com os outros, pela competência para manejar o ambiente e pelo crescimento pessoal. ${ }^{20}$

Ciornai ${ }^{25}$ relata que tanto na arte quanto na terapia, manifesta-se a capacidade humana de perceber, figurar e reconfigurar suas relações consigo mesmo, com os outros e com o mundo, retirando a experiência humana da corrente rotineira, estabelecendo novas relações entre seus elementos, combinando o velho com o novo, o conhecimento com o sonhado, o temido com o vislumbrado, trazendo assim novas integrações, possibilidades e crescimento.

Stuart-Hamilton ${ }^{15}$ ressalta que as razões por trás das mudanças na produção criativa ao longo do período de vida devem-se muito mais ao estilo de vida e às exigências do trabalho da pessoa do que ao envelhecimento em si. As pessoas mais velhas podem ter "perdido" sua criatividade por terem sido muito boas no que faziam antes. Tornase evidente que dedicar-se a uma atividade criativa como pintar, escrever e bordar é de considerável valor para as pessoas mais velhas, aumentando o sentimento de bem-estar e a autoestima.

Segundo Arcuri, ${ }^{26}$ "a arte pode ser uma força capaz de levar o homem além do vazio. É uma linguagem capaz de estabelecer uma conexão com a alma e é a única capaz de compreendê-la”. A arte desenvolve a liberdade à alma aprisionada pelo vazio e pelo medo, levando à construção dos anseios e da necessidade interior do ser humano. Assim, a arteterapia atuaria a serviço das leis da necessidade interior, pois o corpo precisa de trabalho, de fortalecimento muscular e a alma necessita ser fortalecida.

Fortuna $^{3}$ destaca que a arte é necessária ao homem como uma forma de equilíbrio e de integração a seu ambiente: "A arte é o meio indispensável para a união do indivíduo com o todo, refletindo a infinita capacidade bumana para a associação, para a circulação de experiências e idéia".

Para Ostrower, ${ }^{19}$ a criatividade compreende aspectos expressivos de um desenvolvimento interior na pessoa, refletindo no processo de crescimento e maturação, cujos níveis integrativos são considerados indispensáveis para a realização das potencialidades criativa, pois aos processos de maturação se vincula a espontaneidade no criar. Já Philippini ${ }^{27}$ relata que o trabalho criativo interno amplia possibilidades, sendo importante todo o movimento, som, sensações, sentimentos e, os pensamentos neste momento se tornam responsáveis por despertar o ato criador de cada um, e dessa maneira, proporciona um viver de forma mais criativa.

O idoso criativo tem ideias próprias, aceita com mais facilidade os limites do corpo, tem mais cuidado consigo, encontra novas possibilidades e opções agradáveis para desfrutar a vida. Ele dá mais valor aos instantes, presta mais atenção nos detalhes da vida, é dono dos seus desejos e luta por eles, constrói relações positivas que lhe dão prazer, tendo assim maior bem-estar e melhor qualidade de vida. ${ }^{11}$

\section{CONCLUSÃO}

Percebeu-se, através dos relatos, que as idosas melhoraram a habilidade mental, a socialização e diminuíram o uso de remédios, havendo um 
efeito global no organismo humano, uma vez que as atividades do programa promoveram o encontro das pessoas com elas mesmas - ou seja, tornaramse mais equilibradas emocionalmente porque a arte tem o poder de alcançar emoções profundas, dando oportunidade para as pessoas mudarem a maneira como sentem em relação a si mesma e ao mundo. Evidenciou-se que os trabalhos manuais fortaleceram a autoimagem das idosas, através $\mathrm{da}$ concretização dos trabalhos, assim como a socialização, minimizando eventuais impactos decorrentes do envelhecimento e, até mesmo,

\section{REFERÊNCIAS}

1. Rosa MRD, Ribas A, Marques JM. A relação entre o envelhecimento e a habilidade de escuta dicótica em indivíduos com mais de 50 anos. Rev Bras de Geriatr e Gerontol. 2009; 12(3): 331-43.

2. Brasil. Instituto Brasileiro de Geografia e Estatística (IBGE). Perfil de idosos responsáveis pelos domicílios no Brasil. 2000. [acesso 28 set. 2010]. Disponível em URL: < http:// www.ibge.gov.br/home/presidencia/noticias/ 25072002pidoso.sht $>$

3. Fortuna SMCB. Terapias expressivas. Campinas: Editora Alínea; 2000.

4. Eliezer J. Arte-terapia. Rev Insight 1992; 2(23): 21-3.

5. Fabietti DMCF. Arteterapia e envelhecimento. São Paulo: Casa do Psicólogo. 2004.

6. Novaes $\mathrm{MH}$. Autoconceito, um sistema multidimensional hierárquico e sua avaliação em adolescentes. Arq Bras Psicol 1985; 37(3): 27-43.

7. Ministério da Saúde( Brasil). Resolução 196/96 do Conselho Nacional de Saúde/MS Sobre Diretrizes e Normas Regulamentadoras de Pesquisa envolvendo seres humanos. Diário Oficial da União 10 out 1996.

8. Monteiro DMR. Depressão e envelhecimento: saídas criativas. Rio de Janeiro: Revinter; 2002.

9. Santos SSC. Enfermagem gerontogeriátrica: reflexão à cuidativa. 2. ed. São Paulo: Robe Editorial; 2001.

10. Buaes CS, Doll J. Aprende a ser viúva: narrativas de mulheres idosas no meio rural. Rev Kairós 2005; 8(2): 171-88.

11. Camarano AA. Envelhecimento da população brasileira: uma contribuição demográfica. In: permitindo surgir habilidades artísticas e o seu aprimoramento.

Conclui-se, através da categoria "benefícios" e das subcategorias: "habilidade mental", "socialização" e "remédio", que as atividades manuais são valiosas ferramentas na recuperação biológica, psicológica, social e imunológica das idosas. Como possibilidade de novos estudos, sugere-se a aplicação de outras metodologias para verificar novas contribuições que a arte como terapia poderá desvelar no universo dos idosos.

Freitas EV, Py L, Cançado FAX, Gorzoni ML. Tratado de Geriatria e Gerontologia. Rio de Janeiro: Guanabara Koogan; 2002.

12. Quintão MG, Oliveira SAS, Guedes HM. Incontinência fecal: perfil dos idosos residentes na cidade de Rio Piracicaba. Rev Bras Geriatr Gerontol 2010; 13(2): 185-95.

13. Souza OR. Longevidade com criatividade: arteterapia com idosos. Belo Horizonte: Armazém de Idéias; 2005.

14. Carvalho MMMJ. A arte cura? Recursos artísticos em psicoterapia. Campinas: Editoria Psy II; 1995.

15. Stuart-Hamilton I. Criatividade na velhice. 3. ed. Porto Alegre: Artmed; 2002.

16. Urrutigaray MC. Arteterapia: a transformação pessoal pelas imagens. Rio de Janeiro: Wak; 2003.

17. Fortuna SMCB. Doença de Alzheimer, qualidade de vida e terapias expressivas : arteterapia. Campinas: Alínea; 2005.

18. Andrade LQ. Terapias expressivas: arte-terapia, arte-educação, terapia-artística. São Paulo: Vetor; 2000.

19. Ostrower F. Acasos e criação artística. Rio de Janeiro: Campus; 1990.

20. Freire SA. A personalidade e o self na velhice. In: Freitas EV, Py L, Cançado FAX, Gorzoni ML. Tratado de Geriatria e Gerontologia. Rio de Janeiro: Guanabara Koogan; 2002.

21. Branden N. Como aprender a gostar de si mesmo. 18. ed. São Paulo: Saraiva; 1996.

22. Erbolato R, Leite MP. Gostando de si mesmo: a auto-estima. In: Neri AL, Freire SA. E por falar em boa velhice. São Paulo: Papirus; 2000. 
23. Simmons S, Simmons JR, John C. Avaliando a inteligência emocional. Rio de Janeiro: Record; 1999.

24. Sánchez VA, Escribano E. Medição de autoconceito. Bauru: Edusc; 1999.

Recebido: 19/10/2010

Revisado: 03/5/2011

Aprovado: 16/8/2011
25. Ciornai S. Percursos em arteterapia : arteterapia gestáltica, arte em psicoterapia, supervisão em arteterapia. São Paulo: Summus; 2004.

26. Arcuri I. Arteterapia de corpo e alma. São Paulo: Casa do psicólogo; 2004.

27. Philippini A. Cartografias da coragem. Rio de Janeiro: Pomar; 2000. 